\title{
Transformaciones que acontecen en las personas populares de las comunidades
}

\author{
Pedro Trigo, \\ Centro Gumilla, \\ Caracas, Venezuela.
}

Este trabajo tiene dos partes. En la primera se esboza una fenomenología de estos cambios. En la segunda se analizan los cambios respecto a la variable de la modernización. El objetivo del trabajo es mostrar, a partir de un caso concreto, que existen procesos sociales muy variados, que no se definen como modernizadores, pero que incluyen en su dinámica dimensiones fundamentales de la modernidad. El trabajo sugiere que no sería muy dinámico ni fecundo proyectar el proceso histórico deseable para América Latina como un proceso de modernización; pero que si la modernización no debe definir ni totalizar el proceso, no puede, sin embargo, estar ausente de él, sino que la debe contener como dimensión insoslayable.

\section{Fenomenología de las transformaciones}

En las comunidades eclesiales de base no hay espectadores. Pero, aunque todos participan de un modo u otro, es muy diverso el grado de implicación. Aquí nos vamos a referir sobre todo a las personas que están en ellas más activa y cstablemente hasta considerarse y ser consideradas por los demás como las de la comunidad. En ellas aparece de un modo más patente lo que la vida de la comunidad da de sí.

1. Ante todo es constatable el hecho de que la gente cambia. Cambian tanto que suelen aludir a un antes y a un después, afïmando que antes vivían de un modo y ahora viven de olro, que antes eran de un modo y ahora son de otro, que antes eran unas personas y ahora son otras. Así, pues, la transformación se da y es tan profunda que significa una nueva etapa en la vida de esas personas.

2. La transformación se interpreta como un tipo de conversión. No necesariamente de una vida de pecado a vivir como Dios manda. Lo más frecuente es 
pasar de un cristianismo sociológico a otro más personalizado. Incluso en el caso en que se daba una práctica sincera y hasta intensa, ésta era de todos modos una práctica tradicional aceptada. En la comunidad, sin embargo, se redescubre el rostro de Dios y de Jesucristo, y se instaura con ellos una relación interpersonal dinámica, cs decir, que Dios no es sólo el que responde a mis demandas y aquel en quien puedo contiar, sino que tiene un designio para el mundo y para cada persona y lo va revelando en concrelo, progresivamente, si uno se dispone a realizar lo que va viendo en cada momento. Así, pues, el cambio es. en el fondo, la transformación de una relación concreta, la relación con Dios, que se va entendiendo como la relación que fundamenta la vida como globalidad, y por eso, como el principio que la va reestructurando poco a poco. en cada una de sus dimensiones.

Estc cambio, que es la conversión, y los cambios concomitantes son valorados como un acontecimiento extremadamente positivo en la propia vida. Por cso se aprecia tanto la comunidad que lo propicia y salvaguarda.

3. El cambio cs sentido y vivido como translormación. No la introyección de unas pautas, no $\mathrm{cl}$ vestirse de unos símbolos, no el identificarse con unas consignas o un movimiento. No es un dejar lo que se era para vestirse de lo que le propusieron y aceptó. No es una socialización. Es una lenta transformación a partir de lo que se era al tomar contacto con la comunidad; una transformación que cada quien va operando mediante un paciente trabajo sobre sí mismo. Es el propio sujeto el que descubre nuevas posibilidades vitales, el que poco a poco se va decidiendo, va dando pasos, va dejando atrás actitudes o costumbres o relaciones, va tomando posturas, dando razón de sí, asumiendo compromisos...

4. Al Iratar de aclararse a sí misınos y de explicar a los demás la manera cómo va siendo vivido el carnbio, las personas aluden a un salir de un sueño o de una inconsciencia, a un adquirir un conocimiento interno que es mucho más que saber cosas; incluye, sin duda, el conocimiento objetual, pero es sobre todo un progresivo descubrir el mundo de Dios y, a su luz, el mundo propio como una buena nueva que es sentida como gracia, como revelación, y que produce alegría, y que, por ello, lleva a hacerse cargo de lo que se va conociendo. Esta actitud estimula el desarrollo de polencialidades hasta entonces desconocidas. La persona siente con creciente satisfacción como que se estuviera habitando a sí misma, como que fuera tomando posesión de sí. Realmente empieza a adquirir un señorío de sí que la asombra. Al vivir en ese horizonte descubierto y caminar hacia él, la persona va haciendo cosas, desempeñando cometidos, anudando lazos. Verdaderamente, arriba a una nueva existencia social.

5. Este cambio personal sc va realizando en medio de una sensación crecientc de fiagilidad, pues si bien existen modestos éxitos gratificantes, cada nuevo reto es sentido como un salto al vacío. Sin embargo, también se da un cierto

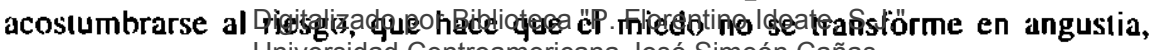
Universidad Centroamericana José Simeón Cañas 
sino que sea inás bien un reflejo saludable de realismo. Porque todo esto se realiza en un ambiente de precariedad, a veces extrema, y teniendo que sobrellevar dificultades propias y del entorno, que una y otra vez amenazan con echarlo todo a perder.

6. El cambio del que hablamos es un proceso que incluye muchas transformaciones capilares, casi imperceptibles, peru que se van acumulando y componiéndose entre sí. No están excluidos, claro está, los atascamientos e incluso los retrocesos; pero cs cierto que, a la larga, si perseveran en el intento, las personas van notando que avanzan; incluso llega un momento en que les parece que no podrían volver a lo anterior, que ya son distintas. Este salto cualitativo contiene diversos niveles. El primordial es, como dijimos, la conversión. A nivel antropológico se expresa sobre lodo como ese señorío de sí que incluye la puesla a disposición de los demás. A nivel de antropología social (que es también en cste caso un nivel eclesial), el punto de inflexión se da cuando la persona se siente parte de la comunidad, cuando la comunidad es una dimensión constitutiva de ella, un ámbito y unas relaciones que llegan a hacerse primarias, generadoras no sólo de actitudes y comportamientos, sino de identidad.

Este salto cualitativo, con las tres dimensiones señaladas, no se realiza siempre con conciencia de sí. Es cierto que el cambio ocurte en uno, pero no está en las manos de uno realizarlo voluntarísticamente. Por eso, ocurre cuando ocurre, es decir, cuando ha llegado el tiempo, no cuando uno quisiera, sino cuando ha llegado la hora, es decir, cuando las cosas han madurado. A veces, la persona se percata, por alguna circunstancia especial (por ejemplo, por alguna reacción suya ante algo que paso), del cambio acontecido en ella y lo recibe con sorpresa agradecida. A veces, sin embargo, es la acumulación de muchos pequeños delalles la que la lleva a la constatación de cuán profundamente cambió. Y no es raro que sean otras personas las que se lo hagan notar y entonces caiga en la cuenta.

7. Esas transformaciones se realizan en la comunidad y, por tanto, la comunidad es luente de esa identidad renovada. Eso ocurre cuando lo que se trae entre manos en ella es denso, tanto que se puede calificar con propiedad de transcendente. S6lo entonces, las relaciones llegan a hacerse primarias y son, estriclamente hablando, personalizadoras. Una comunidad no es un grupo de cristianos que viven en la misma zona y que se reúnen para tratar de cosas de religión y para echarse una mano. En la comunidad hay un empeño transcendente: irse haciendo juntos en Jesucristo hijos de Dios y hermanos, y extender por donde viven la fraternidad de los hijos de Dios. Ese empeño dinamiza la relación y le impide cerrarse sobre sí y volverse intranscendente. Ese empeño vuelve transformadora la relación, y así, es fuente de identidad.

8. El sentido de pertenencia a la conunidad (si realmente es una comunidad

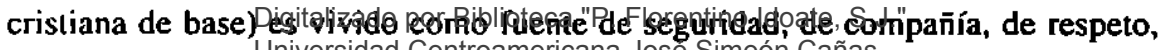
Universidad Centroamericana Jose Simeón Cañas 
de aprecio, como ámbito de esperanza y de crealividad. Como no es el efecto de enfeudarse a una institución poderosa, sino el fruto de llevarse mutuamente sus miembros (es decir, la constatación de la forlalcza en la debilidad), es un ejercicio constante de fe humana, basada en la le divina, y un ejercicio de fe en Dios, alimentada por la mutua le de los hermanos.

Me parece importante precisar este punto. Es, en efecto, distinta la seguridad que se obtiene al entrar en un partido político poderoso o en una gran organización empresarial o en una vasta institución promocional o incluso en un movimiento apostólico de alcance nacional o hasta internacional, que pertenecer a una pequeña comunidad de genle pobre y necesitada como uno. Allí los apoyos son objelivos, es Jecir, se basan en la acumulación de recursos materiales y humanos, en la posesión de influencias, en delínitiva, en el poder. En la comunidad, en cambio, la seguridad proviene meramente del apoyo muluo de sus miembros, teniendo en cuenta que cada quien se siente débil y necesitado a su vez de ayuda. Esto entraña una tremenda transformación, que se asume como una inmensa riqueza, luente de agradecimiento.

Hay una circularidad entre la fe mulua y la fe en Dios, pero es la fe en Dios la que desencadena el proceso. Es verdad que alguien pudo acercarse a la comunidad por la fe en una persona que la invitó; pero si se queda, es decir, si se abre a los demás miembros de ella es porque los va caplando como los hermanos que el Señor le dio. El vehículo fundamental que alimenta, tanto la fe en Dios como la fe mutua, es la escucha orante de la palabra de Dios y sobre todo de los evangelios. Todos juntos, en actitud orante, escuchan cómo la palabra de Dios se proclama a sí misma, cómo Jesús les habla actualmente en ella. Juntos, ayudándose unos a otros, tratan de entender lo que dice y juntos se preguntan lo que les dice precisamente hoy. Al expresar cada quien, en ese tiempo sagrado, lo que Dios le dice, cada quien tiene acceso a la obra de Dios en él y se compromete a ayudarlo a ponerla por obra. Y cuando es al grupo entero al que le habla como tal, el grupo se hace un cuerpo articulado para responder eficazmente. De este modo, se van haciendo a la vez discípulos de Jesús, hijos de Dios y hermanos.

9. En este proceso, una transformación lundamental es que la persona llegue a definirse en la realidad como oyente de la palabra, es decir, que esta dimensión de escucha obediente se convierta en una dimensión permanente y que se vaya extendiendo a las distintas áreas de la existencia. Una persona así se va haciendo una persona atenta, abierta, disponible, una persona de fe. Ya que fe significa escucha de la palabra del otro y caminar en la vida apoyado en ella.

10. Vamos a desglosar ahora los diversos elementos de este proceso. Una Iransformación, frecuentemente expresada con gozo, es la toma de la palabra. Una persona popular vive la experiencia de que nadie le pregunta nada, ni está

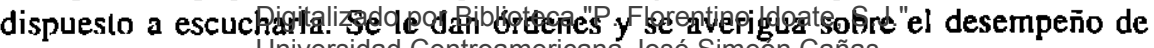
Universidad Centroamericana José Simeon Cañas 
lo gue le encomiendan. Pero no se le pide su opinión. Se sobrcentiende que no lienc nada que decir.

La raíz de la toma de la palabra es la respuesta a la palabra de Dios. La palabra de Dios es libre y crea un ámbito de libertad. Dios no es un amo, ni quiere sicrvos, es decir, ejecutantes mudos. Así como habla, también espera nuestra palabra, nuestra respuesta. Por eso, ia persona cobra ánimos y se atreve a hablar. Al comienzo se habla con miedo: no se consiguen las palabras adecuadas y se teme que los dernás desprecien ese balbucir. Además, se piensa que uno no liene nada relevante que decir. A pesar de todo, sin embargo, poco a poco se comienza a hahlar, y uno es el primero que se asombra de lo que va saliendo de él. Así que, con el ticmpo. uno se siente ya capaz de hablar en público y hablar no lo que se habla (palabras genéricas, impersonales), sino palabras propias y verdaderas que expresan lo que uno es, la propia experiencia o lo que uno siente del grupo o la manera como le afecta una siluación o una propuesta de la que uno inismo se hace cargo...

Al decir palabras verdaderas (aunque los vocablos sean toscos y el discurso parezca mal hilvanado), uno se descubre a si mismo y a la vez se revela a los demás. El que los demás reciban con respeto mi aporte sin reparar en la tosquedad de la forma, sino con la voluntad de entenderme, es una experiencia tremendamente gratificante. Y el entrelazar mis palabras con las de los demás, buscando no salirme con la mía, sino expresar lo que pasa y responder adecuadamente a ello, es una aventura realmente trascendente.

11. La toma de la palabra, se deriva de la escucha obediente, es el preámbulo de la acción. Decidirse a haccr cosas que nunca antes se habían hecho y para las que uno pensaba que no tenía capacidad, es una aventura apasionante. Experimentar que uno puede ir más allá de lo percibido como sus propios límiles es fuente altísima de autovaloración y de alegría. Siempre se va con mucha cautela, porque se tiene miedo al fracaso, pero pequeños éxitos dan pie a que se instaure la apertura y el dinamismo como dimensiones de la persona.

Esta Iransformación estructural es verdaderamente decisiva, porque el punto de partida con frecuencia está signado por la cerrazón del horizonte vital. Muchas mujeres populares se deprimen al verse confinadas en el horizonte doméstico, que sienten que las constriñe drásticamente. Muchos varones viven en estado de frustración al no poder responder a lo que se espera de ellos, porque no hay oportunidades para lo que ellos son y sienten que no pueden ser otra cosa. Por eso, cuando a través de experiencias sucesivas, el horizonte clausurado se abre y se instaura el dinamismo, se puede decir que la persona renace y empieza a brillar la esperanza. Y aunque sea un rayito no más, es mucho cuando se vivía en un túnel o en un pozo adonde no entraba la luz.

Digitalizado por Biblioteca "P. Florentino Idoate, S.J."

Universidad Centroamericana José Simeón Cañas 
12. Cuando el proceso cobra una cierta intensidad y permanencia, la persona miembro de la comunidad es, en cierto modo, una persona pública en el barrio, una referencia no sólo paradigmática, sino pragınática. Naturalmente que esa persona no aspiró a ese status, que además le complica la vida, que de suyo es Ian frágil. Pero lo va asumiendo como una misión, como un componente de su liclelidad, y aprende a procesarlo parlicipativamente. Es decir. no como un pcqueño cacique, sino propiciando la colaboración mutua y el trabajo en equipo desde la dinamización de las personas que parlicipan. Este paso es mucho más difícil que lo den los varones ya que en el imaginario popular establecido no entra esa posibilidad. Cuando se atreve a darlo, sin embargo, como fruto de un proceso, es decir, de la madurez de su translormación personal, csta figura es aceptada y engendra respeto. Pero esto es bastante incipiente aún.

13. Cuando la acción no desplaza a la escucha de la palabra (haciendo cosas en el nombre de Dios, pero no ya desde el contacto vivo con él, sino desde uno mismo que se autoentiende en posesión de la voluntad de Dios), es decir, cuando la acción discernida remite a la escucha renovada de la palabra de Dios para cumplir más adecuadanente su designio, la persona va sintiendo la necesidad de la oración personal en orden a que sea Dios quien dirija la vida. Ya no se trata sólo de pedirle cosas a Dios, ni siquiera de apoyarse en él. Se va sintiendo el deseo de que la vida nazca de él como respuesta a su voluntad actual. Es un paso muy grande el que va de la disposición a cumplir los mandamientos, que están escritos para todos y para siempre, a la relación con él como un alumno que recibe diariamente la tarea de su maestro o un niño que es guiado en cada caso por sus papás. Hay que admitir que este paso no es, de ningún modo, una regresión infantil. No lo guía el temor al uso de la propia capacidad para pensar y decidir. Es, por el contrario, un uso superior, mucho más fino, tanto de la inteligencia como de la libertad. Se trata del alumbramiento de la dimensión de la interioridad, atributo precioso del ser humano. De ahí brota la actitud de recogimiento, que no tiene nada que ver con el andar abstraído, sino que es una atención desde la participación para captar por dónde pasa el misterio y para amoldarse, de modo que vaya aconteciendo en uno. De ahí el silencio inlerior que, al acallar muchas falsas pretensiones del sujeto, permite estar en cada cosa, percibiendo lo esencial y concentrado en darle respuesta adecuada.

Proviniendo muchos agentes pastorales de la reacción a un individualismo malsano y por añadidura insolidario, no fue fácil pasar a la alternativa superadora que integrara esta dimensión, pero saneada y acoplada al conjunto. En no pocas personas populares se daba esta propensión contemplativa. La atención y el cultivo de ella como exigencia del proceso viene siendo para bastantes una reintegración ansiada y gratificante y sobre todo verdaderamente fecunda. Sin embargo, aún falta mucho para que se consolide este proceso en ciemes. 
14. Un momento crucial para alianzarse en esta transformación es cuando la persona se encuentra con límites por haber abarcado demasiado y siente que ya no puede más o que desatiende a la familia, o le sobreviene una desgracia o un problema lámiliar público o cmpeora drásticamente su situación económica o sc enferma... La persona tiene que apoyarse más en Dios y en la comunidad para encontrar un nuevo equilibrio o para procesar el problema con coherencia o para sobrellevar la situación con hidalguía. La percepción de la íntima debilidad personal o situacional hace ver que la Iransfonnación no es lo que tal vez se pensaba. De buenas a primeras, lo adquirido parece un espejismo y es necesario un gran avance para que la persona aceple que sí lleva un lesoro, pero en vaso de harro. Desde la nueva identidad, mortifica verse un paciente pastoral, pero es un mornento decisivo de transformación. Sólo desde ahí, la misericordia es horizontal y mutua, y la solidaridad supera el altruismo.

A veces, el problema surge en la misma comunidad. Pueden ser rivalidades por causa de liderazgo o celos y envidias, o que varias personas que tienen peso se caen mal o tienen opiniones muy divergentes y no quieren dar su brazo a torcer o buscan por todos los medios que se haga lo que ellos dicen, 0 a veces son problemas vecinales o familiares en los que están implicados los mieinbros de la comunidad y aquéllos repercuten en ella... El hecho es que la comunidad, que se vcía como el catalizador del proceso de transformación y el punto de apoyo personal, en un momento determinado, puede convertirse en una piedra de tranca. Este momento, de un modo drástico o discreto, público o solapado, llega siempre, en alguna medida al menos. Es un momento decisivo para ella. Para que salga airosa se precisa que en esa coyuntura, la comunidad se alinque muy explícitamente en sus fuentes, que trascienda, de modo que, poniendo por delante la común paternidad de Dios y la fraternidad que él nos regala y exige. pueda procesarse el problema desde un horizonte adecuado y con el deseo de que se resuelva satisfactoriamente para que todos puedan seguir en ese camino de Dios. Esta trascendencia debe expresarse en esa coyuntura sobre todo como Espíritu: él es el que debe manifestarse como sabiduría, incluso como arle para hallar puentes y caminos para llegar al encuentro y a la superación. Hay que decir que ambientalmente no abundan esos canales y por eso es grave el peligro de que algunas personas se retiren o queden bastante heridas. Hay, con todo, personas que tienen el don de mediar y lograr el avenimiento. Pero es cierto que la comunidad tiene que aprender a procesar los conflictos, si quiere avanzar en complejidad y no sacrificar a una parte de sus miembros. Hay comunidades que lo van logrando. Pero tenemos que reflexionar más explícitamente sobre este aspecto.

15. A la larga, la transformación acaecida trae consigo la adquisición de un Irabajo cualificado. El superar los primeros aprendizajes rudimentarios, el aprender a aprender, el saber hacerse cargo de situaciones, el saber manejar procesos,

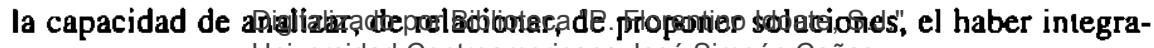
Universidad Centroamericana José Simeón Cañas 
do el equipo, el poder hacer trabajos conjuntos, asumicndo responsablemente la tarea encomendada, incluso el hecho elemental de asistir puntualmente a las reuniones y estar en ellas de una manera activa y producliva... todo esto se valora en el mercado de trabajo o da la posibilidad de cstablecerse exitosamente en cooperativa o por cuenta propia. Así, deseando entregarse a Dios, seguir a Jesús, vivir como hermanos y ayudar a la gente, "por añadidura" se consigue vivir no tan mal y con la seguridad que da la cualificación en los tiempos de crisis.

16. Me voy a relerir ahora a un aspecto que parece intranscendente, incluso pintoresco, pero que, como acontece con regularidad, me parece digno de anotarse por su carácter sintomático. Sucede que a medida que se van dando las transformaciones reseñadas, las personas se presentan más compuestas $y$, concretamente, las mujeres lucen más honitas. El hecho es constatable y de buenas a primeras resulta paradójico, porque no es producto de una acentuación de la coquetería, del ansia de exhibirse y presumir. Acontece, por el contrario, cuando las personas se niegan a sí mismas (dicho en lenguaje evangélico) y se centran en su condición de discípulas de Jesús, de hijas de Dios y de hermanas y desde ahí se entregan a sembrar la vida fraterna de los hijos de Dios. ¿Cómo este olvido de sí coincide con esa floración? Creo que es el síntoma de que la transcendencia cristiana es camino eximio de humanización. La belleza es una manifestación de la gracia. La gracia agracia y eso se expresa hasta en el aspecto externo: el vestido y el semblante. El que se habita a sí mismo y toma posesión de sí, el que es consciente del misterio que se realiza a través de él y se valora como templo del Espíritu, es claro que se trata con respeto y que la armonía interna resplandece con un toque de hermosura. Es obvio que esto no significa gastar más dinero en vestido, calzado y cosméticos. sino que es el resultado de conocer y apreciar más el propio cuerpo y andar con dignidad y a la vez con apertura a los otros, y cuidar más las cosas. En resumen, es una sencilla pero apreciable manifestación de la orientación a la vida verdadera y perdurable, desde las mismas raíces de la persona. Y tanto más destacable cuanto que se realiza en un clima de pobreza.

17. Como resultas de todo este proceso, cada quien va descubriendo su vocación, su carisma, el servicio cualificado que puede ofrecer a la comunidad cristiana y al grupo humano en el que vive, en especial a los que más necesitan. De este modo, la fraternidad descubre con alegría las diferencias peisonales. La alegría proviene al percibir que ellas son su riqueza, porque se dan en el seno del mismo cuerpo social y se experimentan, por tanto, como un bien para el conjunto. Es decir, la gente se individualiza cada vez más y esa individuación se encauza y se torna fecunda en la reciprocidad de dones. Asf, cada quien quiere la diferencia, porque, si no, el compartir sería pobre. La diversidad hace posible que la comunidad se articule como un cuerpo diferenciado en distintas funciones

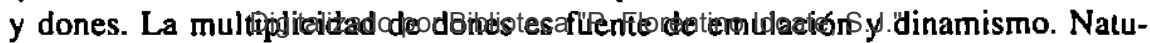
Universidad Centroamericana José Simeón Cañas 
ralmente que ello exige cultivar de manera asidua la transcendencia compartida para que la multiplicidad no lleve a la disgregación, ni la cmulación en lo cualitativo degenere en rivalidades $y$ en lucha por el poder. Este peligro siempre existirá, pero hay que afrontarlo con serenidad desde dentro del proceso, dinamizándolo, porque la comunidad no se puede mantener como algo embrionario, indiferenciado. Si hay lidelidad al Espíritu. la comunidad debe desarrollarse como un cuerpo muy diferenciado y a la vez inutuamente referido y prolundamente trabado. Hay que decir con alegría que. en medio de la precariedad a la que tantas veces hemos aludido, sí existen, sin cmbargo, comunidades así.

18. La trascendencia, que hace posible que las personas se diferencien cualificándose y que encaucen esta riqueza en el servicio mutuo en la comunidad, lleva también a la misión. El amor muluo degenera en egoísmo de cuerpo si los miembros de la comunidad y la comunidad como tal no se derraman fuera de sí. Esta misión tiene dos dimensiones lundamentales que han de ser distinguidas, aunque no se dan ni deben darse completamente separadas. La primera dimensión es el servicio a la vida. Es enriquecer desde la pobreza. Es el donativo de la viuda, que no pocos miembros de las comunidades dan con toda sencillez. Esta manifcstación no puede laltar en las comunidades, ya que es una marca de su genuinidad cristiana. La segunda dimensión de la misión es comunicar el secrelo que ha fecundado la propia vida. Cuando Jesús envía a sus discípulos les encomienda a la vez ambos cometidos. La institución eclesiástica con frecuencia los separa o no los distingue, con grave daño en ambos casos. Reaccionando contra la situación de dominancia, incluso de monopolio, de la institución eclesiástica, no pocos agentes pastorales sienten pudor de comunicar su fe. Es que aún se ven como personas públicas y no hallan cómo hacerlo de modo horizontal. Hay que decir que en el pueblo está la idea de misión. El tiende a comunicar aquello que lc da vida, sea un remedio, una actitud o un fórmula para llegar a un santo. Cuando la comunidad no está clcricalizada, es decir, cuando es realmente de base, se produce la misión como una dimensión constitutiva y primordial. Si la misión se realiza como comunidad, sin rihetes olicialistas, las personas crecen cn ella muchísimo. Lo que existe muestra la lecundidad de este camino. Pero aún puede dar mucho más de sí.

\section{Analisis de los cambios respecto de la variable de la modernidad}

La comunidad liene conciencia de no constituir un ámbito totalizador y menos aún totalitario. Ella es tan signilicaliva que se convierte en fuente de personalización. incluso de identidad social para las personas. Pero no suplanta, sino que estimula el desnudo estar de cada quien consigo mismo y la responsabilidad individual, así como también los vínculos de cada una de las personas con otras comunidades, tanto primarias (como la familia o el paisanaje) como secundarias (la comunidad laboral, la adscripción a un partido o la pertenencia a

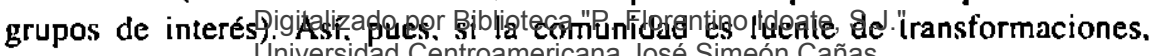
Universidad Centroamericana José Simeón Cañas 
ella no puede dar cuenta. sin embargo, de todas las transformaciones de sus miembros y mucho menos aún de todo el cuerpo social. Incluso al restringirnos a las transformaciones que acontecen a las personas, ni siquiera comentamos otros aspectos de incidencia de la comunidad como tal en el proceso social. Esto debe tomarse en cuenta para no pedir a este análisis lo que por hipótesis no puede dar.

Pero este enfoque restringido tiene, sin cmbargo, la ventaja de permitirnos observar microprocesos, que si bien no se pueden exırapolar, sí pueden arrojar hipótesis estimulantes. La significatividad radica en buena medida en su índole fontal, genuina. No son fenómenos especulares sino que se desarrollan, por así decir, en el fondo de la realidad. De este modo permiten asomarse a acontecimientos genuinamente humanos. Que, por supuesto, no están aislados de otras variables tan decisivas como las que estudiamos, pero que interactúan con ellas desde su propia prestancia.

Al tratar de analizar los cambios reseñados respecto de la variable de la modernización nos encontramos con aspectos que entran dentro de este paradigma; con otros que lo integran, pero desde su propia perspectiva y dinámica, Iransformándolo; y con otros que son más o menos heterogéneos respecto de ella. Al describirlos, iremos viendo cómo los diversos clementos se relacionan y la ligura que componen.

1. Tomamos como punto de partida la realidad del proceso entendido como autotransformación en base a un trabajo de la persona sobre sí misma, que integra los aspectos de salir del horizonte meramente recibido y de la opinión, y arribar progresivamente a la conciencia de sí, de lo sentido como límites propios, y actuar hasta que la apertura dinámica se constituya en dimensión de la persona. Todo esto es medular en la modernidad y acontece también en las personas que siguen consecuentemente el proceso cristiano en las comunidades eclesiales de base.

Para la modernidad ha sido siempre inuy importante la socialización, que consiste, en suma, en ponerse a la altura del tiempo hislórico. Pero como el tiempo histórico en la cultura de la modernidad está signado por la apertura a posibilidades inéditas, la socialización sólo es el preámbulo para la creatividad. La creatividad no consiste únicamente en la transformación de la naturaleza y de la sociedad, sino que contiene como dimensión insoslayable la autocreación del propio sujeto. De este modo, la modemidad asuıne el sentido de la paideia griega, que consistía en propiciar que cada quien hiciera de sí mismo (mediante el uso libre y disciplinado de sus facultades físicas y mentales) una obra de are, y no sólo en el tiempo especializado y por así decir previo de las preparaciones, sino sobre todo a través de su participación en el cuerpo social que era la polis. Así, el ejercicio político (es decir, el desempeño ciudadano) es el acto más

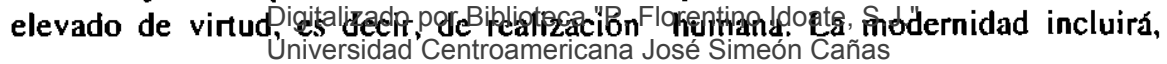


adeınás, Ja entrega a la transiormación de la naturaleza como la otra fuente de autorrealización, no sólo prolesional, sino ética, humana. Todo esto lo retoma programáticamente la ilustración, enlatizando el ajuste de cuentas con la tradición mediante el ejercicio crílico de la inteligencia, pero sin olvidar nunca la primacía de la élica, es decir el objetivo insoslayable de la liberación humana, mediante la praxis iluminada. A través de las generaciones siempre se ha mantenido, en una de las versiones de la modernidad, esla mulua implicación entre la autorrealización y la entrega a la ciencia-técnica y al trabajo productivo y a la interacción social, la creación institucional y la participación y gerencia polílica. Sin embargo, otra versión de la modernidad, más difundida por cicrlo, dicolomiza lo público y lo privado, desconoce la élica como una dimensión universal y vinculante, luncionaliza todo y reduce las opciones a las meras prererencias.

Como se echa de ver, tanto en el proceso de la modernidad como el que se instaura en las comunidades, se da un paso de un modo tradicional y, por tanto, ya dado y constituido de vivir, a la instauración de un horizonte dinámico en el que el sujcto se autoproduce al producir la cultura. La autoconstitución del sujeto es un acontecimiento que sc da $\mathrm{cn}$ ambos procesos. Producir la comunidad eclesial de base y conıribuir a que sc produzca la comunidad barrial y producirlas de un modo personalizado son procesos que lorman parte de la producción de la sociedad.

Hay una diferencia entre las relaciones comunitarias, que son relaciones cortas y las relaciones societales, que son relaciones largas. En éstas, los sujetos inhiben su suidad para constituir el cuerpo social. Sin embargo, no debemos confundir las relaciones que se dan en la comunidad cristiana (hablo de las que más conozco, en los barrios de las ciudades de Venezuela, pero pienso que se podría decir otro tanto de las que existen en otras grandes ciudades latinoamericanas) con el comunitarismo tradicional y menos con la así llamada "solidaridad mecánica". La comunidad cristiana es una creación actual y (aunque en su inspiración más profunda deshorda los marcos de la modernidad) en muchos de sus ingredientes y en el modo de producirse es una creación moderna. Sus integrantes no constituían previamente una comunidad. ni en su convivencia cotidiana ni en el campo especílico religioso. La comunidad esı́́ compuesta por personas heterogéneas, no sólo en edades e idiosincrasias, sino por pertenecer a culturas distintas $y$ en muchos casos positivamente distanciadas. La comunidad no es una institución de molde lijo (como, por cjemplo, la Legión de María o las otras asociaciones y movimientos) al cual se adaptan los integrantes. Por el contrario, la comunidad se va estructurando, a partir de ella misma, en base a la interacción consciente, libre y procesual de sus iniembros. Todos los miembros son. en principio, iguales y, por eso. los distintos papeles van surgiendo por el ejercicio de funciones y se formalizan en base al reconocimiento de su desempe-

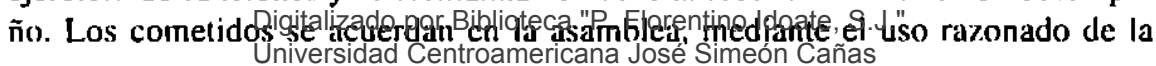


palabra. Y la asamblea va aprendiendo a discernir el peso que tiene la palabra de cada quien, tanto por la capacidad demostrada para desentrañar situaciones y hacer propuestas pertinentes, como por el grado en que la persona se encarga de aquello de lo que se hizo cargo y carga con ello responsablemente.

De este modo en la comunidad se vive, en lo que cabe, una democracia genuina. Una vida diseñada por todos y llevada en común de una manera personalizada, es decir, diferenciada para que sea lo más cualitativa posible, pero $\sin$ que esa multiplicidad de aportes genere privilegios ni discriminaciones, ya que la mayor capacidad se canaliza como servicio que da lugar al reconocimiento, pero no a la asimetría estructural. Además, se intenta llegar a consensos, e incluso cuando hay que votar se procura, siempre que es posible, inlegrar el aporte de la minoría. Esta relación trasparente entre la palabra y el desempeño, que es la pretensión de la democracia moderna, es también el horizonte de la comunidad. La comunidad, en su escucha sostenida de la palabra, es llevada a discernir las palabras desde la carga de realidad que contienen. Y distribuyen y juzgan las tareas y funciones no en base a preтrogativas previas, sino por su desempeño.

Naturalmente, en la comunidad hay conflictos. Su resolución sigue las pautas ideales de las sociedades modernas, es decir, que no se zanjen por el uso discrecional de poderes fácticos, sino en base al examen ponderado de la situación, buscando hacer justicia a las partes y sobre todo tratando de que se resuelva constructivamente. Si el secreto de la política es componer di ferencias, mediar entre las partes y resolver conflictos de modo que de las crisis salga robustecido el cuerpo social, ese es el norte que guía también a la comunidad al procesar sus conflictos. En ambos casos no siempre se logra el intento, pero creo que hay que reconocer que el empeño va más a fondo en la comunidad.

La sociedad moderna ha sido eximia en sus mejores momentos y aun a nivel global en la capacidad de encarar crisis, vengan de fuera de ella, vengan de elementos imprevisibles o imprevistos de su interior. Por su situación en la base y en la periferia social, la comunidad se ve atravesada por siluaciones extremas, que de buenas a primeras parecen imposibles de manejar y que amenazan su existencia. Es cierto que la fe en Dios y la fraternidad entre sus miembros, que han sido los secretos de la comunidad para salir a Jote, no son características modernas; pero sí lo son esas vías democráticas en que se expresan y que la vuelven versátil para procesar las emergencias.

Una contraprueba bastante significativa del grado de modernización alcanzado en el desempeño comunitario lo constituye la mejora económica de muchos miembros de la comunidad como consecuencia de la cualificación profesional como fenómeno concomitante a su valorización humana. Este hecho es tanto más significativo cuanto que el objetivo de la comunidad cristiana no es, obvia-

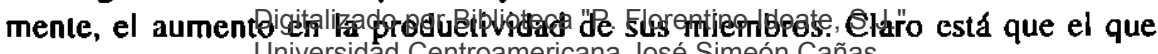
Universidad Centroamericana José Simeón Cañas 
haya más vida y la lucha contra lá pobreza sí Jorman parte del horizonte de la comunidad. Si la productividad como tal, especílicamente considerada, no es lo intentado y, sin embargo, resulta, significa que los medios contenían objetivamente ese ingrediente. Hay que hacer notar que en la versión más integral del proceso de modernización, los dos campos privilcgiados en que se ejercita (el societal y político, por un lado, y el cicntílico, técnico, laboral, por el otro) se caracterizan por su homología csiructural y, de alguna inanera, son trasvasables las acliludes inás genuinas en cada uno de ellos.

Ora característica moderna de la comunidad (aunque su raíz trascienda el horizonte de la modernidad) sería su talante abierto. No es una comunidad tradicional, determinada por la sangre o el lugar de nacimiento o una corporación estamental. Naturalmente que, si es comunidad cristiana, incluye una determinación que la delimita, y así, es una asociación privada y libre. Pero presupuesta esa limitación (que en muchos ambientes de barrio no es percibida como tal, porque lo cristiano es una impregnación ambiental), la comunidad es estructuralmente abierla, de lal manera que sus miembros más consecuentes aparecen en el barrio como personas en cierto modo públicas. como paradigmas y como luente de ayuda, $y$ la comunidad como tal es sentida también como un espacio permeable al barrio y a su disposición. Esto es así porque la comunidad no cobra un peaje religioso por sus servicios y de este modo la variable religiosa que identifica a sus miembros, no funciona como elemento discriminador $y$, por tanto, privatizador de lo público. sino más bien como garantía de lealtad a las personas dentro del ámbilo social de lo en común.

2. En lo reseñado hasta aquí hay coincidencias de londo entre el proceso de la modernidad y el de la comunidad. Hemos indicado, sin embargo, una y otra vez dilerencias de horizonte. Ahora vamos a referirnos a aquellos elementos en los que la diferencia es tan grande como la similitud.

Hemos aludido a que la persona de la comunidad califica su proceso como un pasaje del sueño de la inconsciencia a la luz de la conciencia de sí y de la realidad. Este ingrediente es uno de los que definen más estrictamente a la modernidad. Pero hay una diferencia: la interioridad moderna liene que ver sobre todo con el desdoblamiento reflexivo que separa del mundo y también del yo empírico y los convierte en objelo para el sujeto, y que separa incluso del proceso de conocer, convirtiéndose en conciencia crítica. La interioridad que cultiva la persona en la comunidad es, ante todo, ámbito para que el misterio acontezca en uno. Es un recogimiento, que permile la atención para amoldarse a la actuación del misterio. Desde esa intención trascendente se busca seriamente colocarse al nivel de la realidad, y por tanto, de la verdad y llegar a ellas por todos los caminos que sea necesario, entre ellos también el del conocimiento objetual, el del ensayo y error, y el del control de los propios procesos mentales.

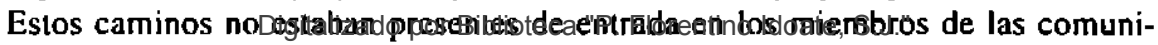


dades. Pero la pasión insoslayable de responder a Dios en la realidad ha obrado como principio modernizador, en el sentido de ir asimilando trabajosamente todos los métodos a su alcance para lograr ese objctivo. En este punto. la gente popular pide ayuda y recibe con avidez lo que se le da.

De igual manera, si el autoentenderse la persona como un proyecto abierto es característica tanto de la modernidad como de los miembros de la comunidad, hay que decir, sin embargo, que son proyectos de diverso modo. En la modernidad radical no existe el relerente de la realidad, y todo es materia prima, en principio moldeable, dependiendo del desarrollo de la ciencia y de la técnica y de la capacidad individual de poscerlas. Con estos presupuestos, el proyecto del sujeto es aleatorio, componencial, guiado sólo por las preferencias. En la comunidad, el proyecto personal es abierto ante todo al misterio y desde él a la rcalidad. Es abierto porque el misterio es libre y luente de libertad y la realidad posec una estructura dinámica. abierta a la creación histórica. Pero no es aleatorio, ni está regido por las prelerencias. Es un proyecto responsable, es decir, la respuesta a una vocación y a una misión, que no son, por supuesto, libretos preexistentes, sino diálogos vivos en el seno de la realidad. El proyecto es un ejercicio de obediencia, pero no a una institución o a un código, no es heteronomía, sino entrega libre y amorosa, que demanda un ejercicio radical de inteligencia y creatividad.

Este proyecto personal lleva en la comunidad y en la modernidad a la integración en un cuerpo social, en el que no se suprimen, sino que encuentran realización las cualidades específicas de cada persona. Este ha sido un gran logro de la modernidad respecto de otras formas societales del pasado, y también es un logro de las comunidades inás evolucionadas respecto de otras asociaciones cristianas. Pero para la modernidad, al no poder lundarse en un ámbito trascendente, este asociacionismo esı́á en función del mutuo provecho; en deઈinitiva, el intercambio de bienes y servicios lo realiza cada quien para su propio benefício, y el secreto de la fórmula está en descubrir que él se obtiene mucho mejor en el intercambio que en una dirección autárquica. La dinámica de la comunidad no desprecia este horizonte; por el contrario, le parece un gran hallazgo; pero, al fundarse su horizonte en la fraternidad de los hijos de Dios, se cncamina a un esquema de reciprocidad de dones, en el que el bien de los demás es un objetivo querido por si mismo. Más aún, al creer que esa fraternidad se extiende a todos los seres humanos, busca extender este esquema más allá de la comunidad, teniendo en cuenta que no se trata de desconocer el de la modernidad, sino de trascenderlo desde dentro.

3. Vamos a referirnos, finalmente, a algunos elementos que caracterizan a las personas de la comunidad, que están ausentes o que son negados en el proceso de modernización. El primero ya lo hemos mencionado repetidamente: la comu-

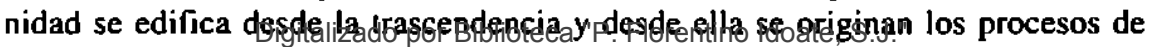

Universidad Centroamericana José Simeón Cañas 
Iranslormación de sus miembros. Se transforman en el proceso de hacerse hijos de Dios en Jesús y hermanos en él. Esto no equivale a ninguna adscripción institucional, ni a profesar un credo, ni a practicar una moral y observar una normativa eclesiástica. Todo esto podrá entrar como ingrediente, pero nada de ello es la fuente. Sólo son mediaciones. La fuente es una relación viva con Dios. Tiene que ver con la modernidad el que la relación sea actual, con un Dios que acontece, y no una relación estaluida con un Dios previsible e institucionalmente a la mano. Tiene que ver también con la modernidad el que la inmersión en el inisterio no sea acosmística, sino que se dé en la realidad histórica. Pero desborda el horizonte de la modernidad la prelensión de hacer una historia con Dios, porque Dios hace historia con nosotros. Y esa es la experiencia desde la que los miembros de la comunidad van construyendo su humanidad cabal.

Desde esta actitud primordial, su relación con la Biblia no es la que ha caracterizado a la modernidad. Ellos son oyentes de la palabra; su actitud es la lectura orante. La modernidad, en cambio, se ha enfrascado en el estudio objelual, una relación de sujeto a contenido, sin ningún presupuesto, tratando de poseerlo. En las fases preliminares, tal vez los miembros de la comunidad se decían a sí mismos con el punto de apoyo de la palabra. Pero esto se agota pronto. Las comunidades que duran y avanzan, escuchan realmente la palabra. Ellas no entienden la posibilidad de dominarla. Pero, precisamente porque desean escucharla en verdad, se abren a toda contribución, en orden a entender mejor lo que dice en realidad, porque lo que les dice no puede ser ajeno a lo que dijo en las primeras comunidades.

De este modo, si se basa en la escucha obediente de la palabra, la relación con la trascendencia es una relación de fe. Porque existe esa fe, se busca con ahinco lo que dice la palabra y en general se vive en actitud de discernimiento para ver cuál es la voluntad de Dios y por dónde sopla su Espíritu. Pero porque se vive con fe, no hay ninguna ansiedad por remontarse más allá de la palabra, ni por conocer presuntos secretos divinos, que él no ha tenido a bien revelar. No se busca conocer a Dios como un modo de dominio sobre él. Se deja a Dios ser Dios (lo mismo que él nos deja que seamos nosotros), porque se confía totalmente en él. Esta actitud de fe radical respecto de Dios es el fundamento de la fe humana como base de relación entre los miembros de la comunidad y asintóticamente con todos, en un proceso lento y contrastado.

No parece que la fe signe el modo de relación en la modernidad. Precisamente porque no se la da por supuesta, están las reglas de juego precisas a las que cada quien se compromete y las correspondientes sanciones para que resulte más diffcil o arriesgado no cumplir que cumplir con lo pautado. En vez de la $\int e$, el prototipo de relación es el ajuste contractual. Precisamente, el paulatino entrar en un horizonte de fe en las relaciones mutuas como correspondencia a la fe que Digitalizado por Biblioteca "P. Florentino Idoate, S.J."

Universidad Centroamericana José Simeón Cañas 
se va teniendo en Dios es una de las experiencias más gratificantes de la comunidad y fuente en buena medida de su cstabilidad y dinamicidad.

Otra heterogeneidad radical de la comunidad respecto de la modernidad es que son procesos personales, que se dan entre los de abajo y a partir de ellos. Es cierto que la relación no ilustrada de los agentes pastorales con ellos constituye no sólo un catalizador del proceso. sino un elemento permanente del mismo. Pero eso no obsla para que la relación se dé en la casa del pueblo, es decir, en su cultura y en su cotidianidad y para que (si la comunidad se mantiene como realmente de base) la gente popular tenga la voz cantante.

La modernidad no cree posible que los de abajo sean una magnitud cualitativa y menos los pobres modernos de las periferias de las grandes ciudades. Tal vez sca cierto mucho de lo negativo que la modernidad dominante dice de los de abajo. Nosotros hemos insistido a lo largo de estas notas (y lo repelimos ahora sin ningún empacho) en la inocultable fragilidad de todos los procesos por la precariedad vital que tiende a volverlo todo delicuescente y propicio al desmoronamiento. Ciertamente, todo es dificultoso y lento. Más aún, en esas condiciones ian duras, lo ordinario es que la fidelidad no sea algo que se adquiera de una vez. por todas, sino un punto de llegada. En muchas ocasiones, la vida no da para más y es mucho. incluso, que dé para eso. Pero, ciertamente, por más aspectos negativos que se resalten, eso no es todo ni lo delerminante. La modernidad más generosa pretende salvar a los de abajo por su progresiva asimilación a los de arriba. Desde la experiencia de las comunidades, nosotros afirmamos que los de abajo necesitan, ciertamente, de los integrados en la ciudad moderna, pero afirmamos también que la modernidad necesita ser exorcizada de sus demonios y que sólo los pobres con espíritu serán capaces de liberarlos de ellos. Por eso. la modernización integral conduciría a la condenación de la humanidad.

Concretamente, estos pobres con espíritu aportan, entre otras, tres dimensiones primordiales, ausentes de la modernidad y también del cristianismo establecido (moderno o premoderno). Son las dimensiones de realidad, de fe y de gracia. La modernidad confunde el orden establecido con la realidad y, por eso, lo que está al margen le parece excepcional, residual, $y$, sin embargo, constituye el 80 por ciento de la humanidad. La modernidad lo sabe sólo de manera objetual (de ese modo es la que mejor lo sabe), incluso la parte más generosa de ella puede encargarse encarecidamente de ese problema. Pero como en su vida privada da por supuesto la vida y se dedica a la cualificación en la producción y en el disfrute, no puede vivir al nivel de la realidad en el que el tema es seguir viviendo. Ese nivel le está cerrado en su mundo de vida, en su comunidad viviente y sólo puede acceder a él a través de la información o del trabajo profesional o de la ayuda. Pero ninguno de esos modos le permite entrar en su

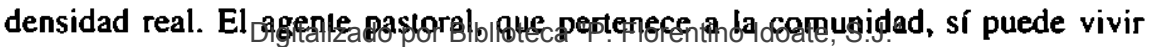
Universidad Centroamericana José Simeón Cañas 
en la realidad, si las relaciones en la comunidad son tan decisivas para él que lo conliguran como persona.

Si se sitúa a este nivel, descubre también lo que significa vivir de fe. Descubre que se puede vivir de fe, es decir, que Dios es un apoyo real, aclual, que mantiene en pie la vida física y posibilita su calidad de humana. El agente pastoral puede presuponer su $\mathrm{Te}$, pero ordinariamente no tiene cómo saber que se apoya en realidad en Dios. Como tiene muchos apoyos en la vida, no puede comprobar que Dios es el apoyo radical y los demás son sólo mediaciones. El agente pastoral puede hablar sobre Dios entusiásticamente, puede incluso hablar a Dios; pero fuera de casos excepcionales, no puede hacer la probación física de Dios. Por esos pobres con espíritu sabe en realidad que Dios existe y, por tanto, que existe el milagro. Esa experiencia da a la vida un peso que permite que cada cosa cobre sus proporciones propias, ya que uno no se aferra a ellas para salvarse.

Desde esta experiencia de que se puede vivir de fe, se abre olra experiencia desconcertanle: se puede dar desde la pobreza, se puede dar lo que no se tiene. se puede dar de una manera incondicionada y a la vez desnuda y humilde. Es la experiencia de la gracia. La modernidad conoce el altruismo, no la gracia. 